\title{
Study on Competence of SME Managers in Middle Science and Technology Enterprise
}

\section{Mingyue Li}

Tianfu College of swufE, Mianyang, Sichuan, 621000

\author{
Keywords: Competence, SME Manager, Middle Size Enterprise
}

\begin{abstract}
Small and medium-sized technology-based SMEs play an important role in promoting innovation and development in our country. With the development of small and medium-sized technology-based enterprises, human resource management, as an important function of business management, has become one of the important factors restricting its development. The important reason is that the competence of human resources managers of SMEs in science and technology does not adapt to the rapid development of enterprises. Therefore, it is necessary to study the competence of human resources managers in SMEs. Based on the in-depth analysis of the competency of competency and human resources managers at home and abroad, this study takes the human resources managers of small and medium-sized technology enterprises as the research object, and takes the methods of literature research, behavior interviews and questionnaires, Empirically explores and studies the competencies of human resource managers in science and technology SMEs. Taking the combination of theory and evidence, this paper discusses the competencies necessary for human resource managers of SMEs to achieve outstanding performance, determines the weight of competency elements through AHP, and finally builds the human resources management of SME Competency model.
\end{abstract}

\section{Introduction}

As an important part of small and medium-sized enterprises, science and technology SMEs are the most dynamic, most potential and most growth-oriented innovation groups. They are the most important subjects for absorbing and giving birth to scientific and technological achievements and the effective realization of technological innovation Vector. Small and medium-sized technology-based SMEs play a very important role in promoting the development of science and technology in our country and have not played any role in promoting the improvement of people's livelihood in the national economy. However, many problems have also been encountered in the development of S \& T SMEs in our country, such as the difficulty of cultivating innovative talents, the loss of markets, the need to improve the management level of enterprises, the absence of relevant state policies and so on. In recent years, science and technology enterprises have become increasingly valued by governments and academics. However, regardless of the focus of state support for science and technology SMEs, the focus of science and technology SMEs on their own development is the focus of scholars on science and technology SMEs, most of which focus on financing and technological innovation, etc., The management of small and medium-sized technology-oriented enterprises less attention. Compared with financing and technological innovation, with the expansion of the scale of science and technology small and medium enterprises, management has gradually become the bottleneck restricting the development of science and technology SMEs, how to enhance management capabilities, strengthen core competitiveness, and become a science and technology development needs of small and medium enterprises Solve the important issue. Under the circumstances of economic integration, information diversification, market innovation and competition, the key to the development of science and technology enterprises and small enterprises depends not only on whether the enterprises are financially supported by their core technologies, research and development capabilities, I $\perp$ depends on whether the enterprise has a first-class person to recognize the seven meals, a high quality of human 
resources and the night; level. Therefore, for SMEs in science and technology, the management of human resources has become an important management content such as financing and technological innovation. However, human resource managers, as the main break of human resources management in SMEs, play an important role in guaranteeing the normal and efficient operation of human resources management in enterprises. Therefore, it is necessary to determine the standards for employing SMEs to select and train human resources managers of SMEs in science and technology to improve the human resources management of SMEs, improve the human resources management level of SMEs, and promote the development of small and medium-sized SMEs The healthy development of enterprises will play an important role in promoting.

\section{Competency Model Building Overview}

Competency model building is a dynamic and systematic work. By building competency model, enterprises find out the gap between the actual competency and the competency requirements. Organizing targeted training can effectively promote the career development and ability of employees, so as to improve their performance and achieve a win-win situation between enterprises and employees. Therefore, building a competency model on the basis of mastering the system's model building process, standard model building principles, and scientific model building methods can help employees improve their competency level and facilitate the smooth and effective completion of various tasks, The cause of healthy development.

Although the concept of competence and quality has been widely disseminated and applied in academic and business circles in our country, it has had little effect in the management and application of many enterprises. The reason is related to the relative research results of domestic and foreign students who apply hardworking. The determination of competency elements is the basis of constructing competency model, and objective and scientific definition of competency elements can ensure and enhance the practicability and effectiveness of the model. Therefore, this study follows the principles of pertinence, scientificness, elemental refinement and avoidance of duplication in determining competence of human resources managers of SMEs in science and technology. Targeted principles. In view of the characteristics of small and medium-sized technology-based SMEs and human resources managers SME design wins the element of power, build SME human resource managers competency model. Scientific principle. Based on the theories of management science, psychology and other related disciplines, combined with the achievements and experiences of domestic and foreign researches on competency and HR competency research, the author uses scientific methods to design competency elements and build human resources of science and technology SMEs Managerial competency model. Elements of refinement, to avoid duplication of principles. Small and medium-sized SME human resources managers competencies elements should be prepared highly summarized and concentrated. Each competency factor for agricultural science and technology tips Small business human resource managers competency varies, try to avoid duplication of competencies.

\section{Science and Technology SME Human Resources Managers Competency Solutions}

Based on the competency model, human resource managers of small and medium-sized technology-based SMEs should set up a system that includes basic skills and teamwork (ability to promote cooperation, build up internal relationships, be willing to share, communicate and learn. Employee's sense of service, responsibility and influence), professional knowledge and skills (human resource expertise, legal knowledge and legal management ability, establishment and execution of human resources management system, computer operation ability), strategic thinking and action (change management, Method innovation, strategic thinking, achievement of objectives, public relations ability), learning ability, technical knowledge involved in the enterprise, continuous learning ability and business knowledge). This competency, led by the building of an all-round capability system, on the one hand challenges the human resources managers of small and medium-sized technology-based SMEs and on the other hand, can help SME human resource 
managers to find their own direction of efforts, Which perspectives consider the development of human resource management capabilities, thereby enhancing their human resource management competencies.

In enterprises, however, the focus of human resources management is different, but all the work is indivisible, and any one of the missing links will lead to the imbalance of the entire human resources management system. Only when all human resources management work is in place and adjusted according to different situations can we ensure the benign operation of enterprise human resources management and support the ultimate realization of enterprise strategy. From this perspective, it is very important to foster human resources management system and improve the overall human resources management level of human resources managers in small and medium enterprises. The establishment of human resources management system based on the premise that the company, including senior managers, grass-roots employees, including all employees: to enhance the existing concept of human resources management, to raise awareness of human resources management, attaches great importance to human resources management work on science and technology At the same time, it is necessary to clarify the relationship between human resource management and corporate strategy, corporate culture and overall management of enterprises.

Job analysis is the foundation of human resource management and an important condition to enhance the competency of human resource managers in small and medium-sized technology-based SMEs. Through job analysis, job responsibilities, job descriptions, job relationships and job qualifications can be clarified. Therefore, the use of SME human resource managers competency model analysis of human resources management positions will help determine the qualifications of SME human resources management positions and specific job competency requirements, so as to develop a more complete Qualifications and job descriptions and other personnel documents. Through clear job responsibilities, to determine job descriptions to enhance competence of human resources managers of small and medium-sized technology-based SMEs, and role in human resource management in all aspects. It is an important basis for formulating human resource planning for small and medium-sized science and technology enterprises. It provides a reference standard for recruiting and selecting human resources managers for small and medium-sized technology-based SMEs and clarifies the content and direction of human resources managers' training and development in small and medium-sized science and technology enterprises It provides the basis for performance-based standard setting and performance management of human resource managers in small and medium-sized technology-based SMEs. It is the premise and basis of salary design of human resource managers in small and medium-sized technology-based SMEs. The job responsibilities associated with the competence of human resources managers of SMEs are to identify the characteristics and behaviors associated with outstanding performance by researching the employees with excellent performance and to define the characteristics of science and technology Responsibilities of human resources management positions, with strong predictability of job performance.

Human resource managers are the main body of human resource management in small and medium-sized science and technology enterprises. The improvement of their qualities helps to improve their human resource management level. Therefore, human resource managers play an extremely important role in the improvement and development of human resource management in enterprises. The improvement of the quality of human resource managers in SMEs helps them to improve their working ability and competitiveness. Training is an important way to improve the quality of human resource managers in small and medium-sized technology-based SMEs. By improving the quality of their staff, training can make the work of the enterprise productive, maintain the survival of the enterprise, and promote the development of the enterprise. From the organizational level, through training to improve the competency of human resources managers in small and medium-sized technology-based SMEs to meet the requirements of job competency, they can better perform their duties and contribute to the realization of performance standards and realize the staff-job-organization Matching; From the personal point of view, training to improve the skills of SME human resources managers competency level, to meet the original post or new job 
competency requirements, and thus achieve personal career development.

The basis of setting up SME human resource managers competency model is to extract competency factors of human resource managers of SME in science and technology, which distinguish between excellent performance and common performance. Therefore, small and medium-sized technology-based SMEs can adopt the performance appraisal index of SME human resource managers established on the basis of competency model, reflecting the essence of performance appraisal and truly reflecting the comprehensive performance of human resources staff. In addition, the feedback of performance appraisal can serve as a basis for further promotion and development of competencies, and the two are mutually reinforcing. When the outstanding performance of human resources managers active efforts to get timely repayments, you can improve and enhance their enthusiasm. For HR managers with poor job performance, they improve their performance based on the performance appraisal standards and competency model, so as to achieve the expectation of the staff to the staff so as to ensure the long-term business performance. Therefore, in the assessment of human resources managers in science and technology SMEs, the index of competency development should be included in the assessment content. For the achievement of performance appraisal standards of human resource managers, should be given the appropriate reward.

\section{Conclusion}

As one of the important management functions of an enterprise, human resource management of small and medium-sized technology-based SMEs affects the overall management level of SMEs in a certain extent. However, through the investigation and research, it is found that the quality of human resource managers of SMEs in science and technology is far from being able to meet the needs of excellent human resource management. Through in-depth analysis and research, this study determined the SME human resources managers competency scale, using empirical analysis method to test the scale to build the final SME human resource managers competency model. At the same time, measures to enhance the competency of human resources managers in small and medium-sized technology-based SMEs are proposed in the aspects of strengthening all-round capacity building, establishing a human resources management system, clarifying job responsibilities, strengthening training, and perfecting performance appraisal and incentive systems.

\section{References}

[1] Liao Shichao. Venture Capital Project Evaluation Manager Quality [J]. Science Management Research.2002 (03)

[2] Cai Ning, Ruan Ganghui. Core competitiveness of SMEs and its comprehensive evaluation system [J] .quantitative economic and technical economic research. 2002 (05)

[3] Fan Xiangru. Evaluation of venture capital projects [J]. Journal of Central South University of Technology (Social Science Edition). 2002 (01)

[4] Tang Zhirong, Chen Suhua. Research on the evaluation index system of enterprise informatization level [J]. Science of Science and Management of S. \& T. 2002 (03)

[5] Hui Xiaofeng, Zhang Zhenwei, Wei Hu. Broaden the direct financing of small and medium technology enterprises research [J]. China soft science .2002 (03)

[6] Zhou Xiaohong, Chen Xijun. Application of Option Theory in Venture Capital Project Evaluation [J]. Operations Research and Management. 2002 (01)

[7] Zhang Wei, Ye Ming. High-tech enterprises equity incentive [J]. Science and Technology Management. 2001 (11) 